\title{
Case Studies of Cavity and External Wall Insulation Retrofitted Under the Irish Home Energy Saving Scheme: Technical Analysis and Occupant Perspectives
}

\author{
Aimee Byrne \\ Technological University Dublin, aimee.byrne@tudublin.ie \\ Gerard Byrne \\ $T C D$ \\ Garrett O'Donnell \\ $T C D$ \\ Follow this and additional works at: https://arrow.tudublin.ie/engschcivart

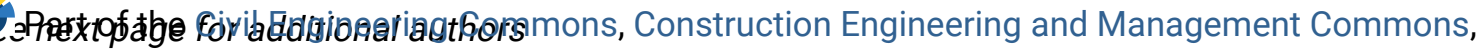 \\ Dynamics and Dynamical Systems Commons, Environmental Engineering Commons, Human Geography \\ Commons, Oil, Gas, and Energy Commons, Other Civil and Environmental Engineering Commons, Other \\ Engineering Science and Materials Commons, Other Materials Science and Engineering Commons, \\ Quantitative, Qualitative, Comparative, and Historical Methodologies Commons, Structural Engineering \\ Commons, Structural Materials Commons, and the Sustainability Commons
}

\section{Recommended Citation}

Byrne, A., Byrne, G., O'Donnell, G. and Robinson, A. (2016) Case studies of cavity and external wall insulation retrofitted under the Irish Home Energy Saving Scheme: Technical analysis and occupant perspectives, Energy and Buildings, 130, 420-433, 2016. doi:10.1016/j.enbuild.2016.08.027

This Article is brought to you for free and open access by the School of Civil and Structural Engineering at ARROW@TU Dublin. It has been accepted for inclusion in Articles by an authorized administrator of ARROW@TU Dublin. For more information, please contact arrow.admin@tudublin.ie, aisling.coyne@tudublin.ie, gerard.connolly@tudublin.ie.

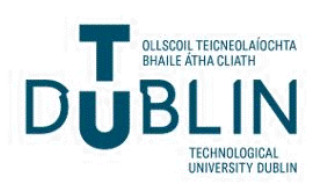




\section{Authors}

Aimee Byrne, Gerard Byrne, Garrett O'Donnell, and Anthony Robinson

This article is available at ARROW@TU Dublin: https://arrow.tudublin.ie/engschcivart/78 


\title{
Case studies of cavity and external wall insulation retrofitted under the Irish Home Energy Saving Scheme: Technical analysis and occupant perspectives
}

\author{
Aimee Byrne ${ }^{\mathrm{a}, *, 1}$, Gerry Byrne ${ }^{\mathrm{b}}$, Garrett O’Donnell ${ }^{\mathrm{b}}$, Anthony Robinson ${ }^{\mathrm{b}}$ \\ a Department of Civil \& Structural Engineering, Dublin Institute of Technology, Ireland \\ $\mathrm{b}$ Department of Mechanical and Manufacturing Engineering, Trinity College Dublin, Ireland
}

Published in:

Energy and Buildings 130 (2016) 420-433

\begin{abstract}
A B S T R A C T
The residential sector represents $27 \%$ of primary energy consumption in Ireland. This paper examines the case study of the Irish government's national grant scheme to encourage energy efficiency retrofit in private housing. That is the Home Energy Saving (HES) Scheme, later rebranded the Better Energy: Homes (BEH) Scheme. The methodology involved monitoring several homes immediately before and after retrofit alongside discussions with occupants. The examination focused on specific measures commonly introduced through the HES/BEH programme - cavity and external wall insulation. It has been found that a significant decrease in heat loss through the walls was measured in all cases. Regardless, the occupant played a considerable role in the change in energy use in the buildings, and the main motivation for retrofit was found to be comfort and not energy savings or environmental concerns. As a result, the actual energy savings are notably less than the potential savings had the pre and post comfort levels remained the same.
\end{abstract}

\section{Keywords:}

Retrofit

Insulation

Thermal comfort

Occupant

Heat loss

Energy efficiency policy
In 2006, the Greener Homes Scheme (GHS) was launched offering grants to homeowners for the installation of renewable technologies. In 2008, SEAI launched the Government's Home Energy Saving (HES) pilot scheme [4] with full rollout in 2009 offering grants to supplement the cost of energy saving features in the home.

In May 2011, the Better Energy Programme replaced the three private residential retrofit schemes. The GHS effectively ended, although solar heating support was continued along with the features offered under HES under one scheme, branded the Better Energy: Homes $(\mathrm{BEH})$ scheme, with most grant levels reducing by $20 \%$ later that year. The WHS was subsequently rebranded the Better Energy: Warmer Homes (BEWH) scheme. At the beginning of the research and monitoring for this article, grants were at the original level shown for the HES scheme in Table 1 but part way through the testing period the grant levels are as shown for the BEH scheme in the same table.

\subsection{Energy use in the home}

The determinants of home energy use are complex. It is the product of interaction of occupants, the building, equipment and climate leading to different behaviour and energy use [5]. Occupant factors include, age, income, education, gender, awareness and comfort. Building factors include size, type, age and location. 
Table 1

Grants available through the HES and BEH schemes.

\begin{tabular}{|c|c|c|}
\hline Measure & HES 2009-2011 grant & BEH 2011-2015 grant \\
\hline Roof Insulation & $€ 250$ & $€ 200$ \\
\hline Cavity wall insulation & $€ 400$ & $€ 250$ \\
\hline Internal Wall Dry-Lining & $€ 2500$ & $\begin{array}{l}\text { - Apartment (any) OR Mid- terrace House } € 900 \\
\text { - Semi-detached or End of Terrace } € 1350 \\
\text { - Detached House } € 1800\end{array}$ \\
\hline External wall insulation & $€ 4000$ & $\begin{array}{l}\text { - Apartment (any) OR Mid- terrace House } € 1800 \\
\text { - Semi-detached or End of Terrace } € 2700 \\
\text { - Detached House } € 3600\end{array}$ \\
\hline High Efficiency Gas or Oil fired Boiler with Heating Controls Upgrade & $€ 700$ & $€ 560$ \\
\hline Heating Controls Upgrade & $€ 500$ & $€ 400$ \\
\hline Solar heating & Available under GHS & $€ 800$ \\
\hline An after works Building Energy Rating (BER) assessment must be completed & $€ 200$ & $€ 50$ \\
\hline
\end{tabular}

Each of these impacts energy use in the home [6-13]. Historically in Ireland, building design mainly focused on meeting aesthetic and functional needs over thermal performance of the design. The first national building standards in Ireland were introduced by the Building Control Act of 1990 [14]. 74\% of dwellings in Dublin were built before the first Building Regulations in 1991 [15]. Part L of the Building Regulations was first introduced more recently in 2005 [16]. It refers to the conservation of fuel and energy giving minimum requirements for energy efficiency standards and Building Energy Rating (BER) grades for new buildings as well as change of use and material alterations of existing buildings. Energy efficiency, thermal comfort and sustainability are more recent trends as highlighted by the shift in political and industry discourse in Ireland. The propensity of occupants to undertake energy efficiency retrofits in their home is dependent on a similarly long list of interacting factors [14-21]. It is thus understandable why the potential energy savings due to retrofit are difficult to quantify with any degree of accuracy since it relies on such a large and typically uncontrolled number of variables [22].

When it comes to energy retrofits in Irish homes, grants for insulation constitute the highest pay-out by SEAI [23]. Moreover, according to the EU Action Plan for Energy Efficiency, wall and roof insulation offer the greatest opportunity to save energy and reduce emissions in this sector [24]. The scope of this project was therefore reduced to homes receiving either cavity wall or external insulation due to limitations in resources and with the aim of limiting variables. A few basic concepts of energy use in the home must first be understood before describing the methodology designed for this study.

\subsubsection{Heat flow through the building envelope}

One-dimensional, steady-state models can be used to represent the plane or composite wall [25], or other building envelope material. Heat is transferred to the wall's inner surface by convection from the warm air, by conduction through the wall, and by convection from the outer surface of the wall exposed to the cold air. In the case of Fig. 1 the 'hot air' is the internal heated space and the 'cold air' is the external colder ambient air. In a simple steady-state scenario, where the one-dimensional thermal resistance network model is applicable, the heat transfer can be estimated provided that each thermal resistance can be approximated and the interior and outdoor temperatures are known. Of course, increasing one of the thermal resistances or the addition of an additional thermal resistance will increase the overall thermal resistance and thus reduce the heat transfer for given indoor and outdoor conditions. Since the rate of heat transfer dictates the net energy transfer over a given time period, retrofit measures are aimed to reduce the rate of heat transfer, typically by the addition of a layer of insulation, such as external wall or roof insulation, or filling a wall cavity will insulating material.

Although steady one-dimensional models give insight into the expected thermal behaviour of building envelope material and are simple to use and implement in predictive calculations, they may not in all cases be physically representative of the actual thermal phenomena. Many heat transfer scenarios are time dependant, or transient. Transient effects must be considered when boundary conditions change at a rate which is faster than that which the building envelope can respond. Walls, or indeed other building envelope types, with high thermal mass have the capacity to store and release heat which changes the dynamics of the heat transfer and energy flow compared with steady or quasi-steady systems [26-28]. Thermal admittance is a measure of a material's ability to take in and store heat from a space and releasing it back to the space over time. It is therefore an indicator of the storage capacity of that material. In reality, buildings rarely achieve steady-state conditions as internal and external environments fluctuate, usually cyclically, faster than the envelope material can respond $[26,29]$. This leads to transient heat transfer within the wall. The implication is that, when considering the influence of thermal insulation on the overall influence of energy flow through building envelope material, significant error can occur on any subsequent energy analysis when steady thermal network models are imposed on inherently

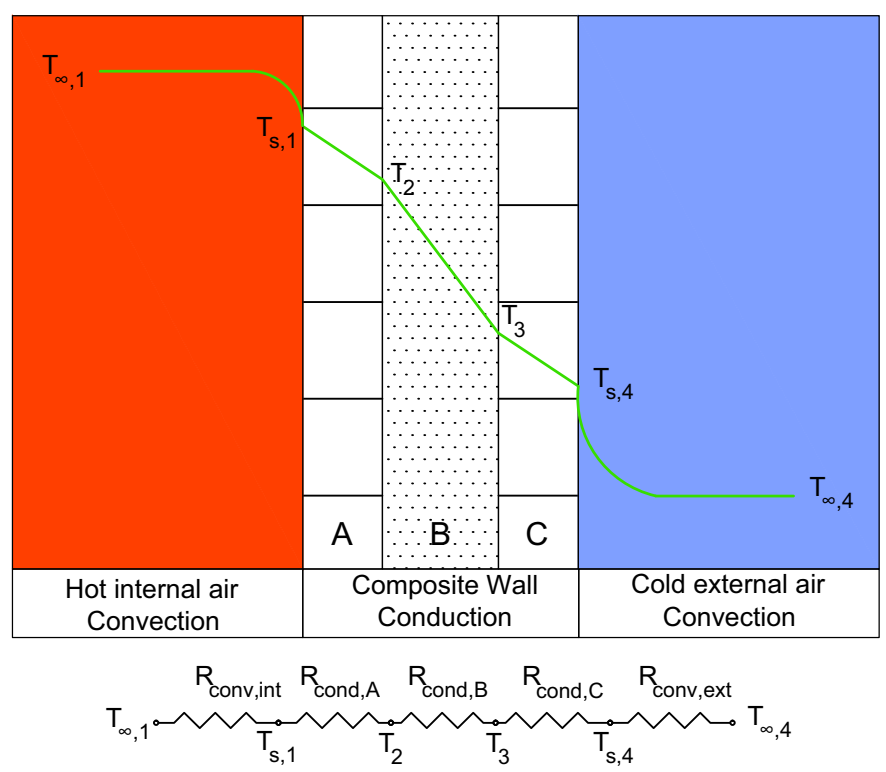

Fig. 1. Thermal network representing heat flow through a generic composite wall system made up of 3 materials, A-C. 
transient systems [26]. Decrement factor is an important measure to consider during cyclical heating periods. It is the ratio between the temperature fluctuation on the outer and the inner surface of the wall and therefore an indication of the damping effect. Generally, the higher the thermal capacity or the higher the thermal resistance of a material, the stronger is the damping effect.

The envelope in a typical house comprises the windows, walls, roof and doors. The ability of these structures to resist heat flow is generally termed as its thermal resistance, or R-value. This is related to the inverse of its effective thermal conductance, or Uvalue. Insulation, being a substance of low thermal conductivity, is used to increase thermal resistance of the wall and ceiling systems by restricting the flow of heat between the cold outdoor and warm indoor environments. By reducing the heat transfer, less energy is lost to the outdoors for ostensibly the same conditions which will proportionately reduce the cost of heating the building i.e. maintaining it at a comfortable temperature. Conversely, a wellinsulated building can provide improved comfort for equivalent or possibly reduced energy expenditure for heating. Cavity wall and roof insulation are generally considered as simple and effective retrofit opportunities when it comes to insulating the building envelope due to cost and ease of installation [30,31]. External insulation is regarded as the better option if a cavity is not present in terms of thermal performance [32,33], and difficulties in installation internally which can lead to mould growth if not properly designed [34].

\subsubsection{Occupants}

"Thermal comfort is that condition of mind which expresses satisfaction with the thermal environment" [35]. It is personal and perceptual and therefore impossible to exactly specify, yet it is dependent on a large number of measurable variables. There is a wealth of research in the area of what thermal comfort is, its relation to outdoor conditions [36,37], profile of the subject [38] and activity of the subject [39] amongst many other variables [35,40-45]. The most significant influence on indoor comfort is the air temperature. A single acceptability threshold for this has not been standardised for building regulations in Ireland, instead acceptable ranges are between $16{ }^{\circ} \mathrm{C}-23^{\circ} \mathrm{C}$ depending on age of the building, use of the space and the occupant profile and behaviour $[41,46,47]$. Furthermore, humidity can change the apparent temperature as sensed by the occupants. A $10 \%$ increase in relative humidity is perceived to be up to a $0.3^{\circ} \mathrm{C}$ rise in temperature [35]. However, in temperate climates, such as those generally experienced in Ireland, humidity only has a modest impact $[35,41]$

According to Clinch and Healy [48], if it is assumed that all dwellings are already heated to the occupant's preferred temperature it can be presupposed that any energy efficiency programmes will result in a reduction in energy consumption and related emissions. However, if a portion of the housing stock is heated to sub-thermal comfort levels for that occupant, any retrofit programme may result in a portion of the potential savings being used to achieve thermal comfort. Fuel consumption may remain the same or even increase as users may now choose to heat the entire house as opposed to a portion of it. Occupants may also use the same amount of energy to achieve more comfortable conditions overall, known as "comfort take-back" [49]. Comfort take-back is a major cause of the rebound effect, a phenomenon whereby households consume more energy than predicted after energy effeciency upgrade. Considering the above, it is important to combine quantitative measurable results such as temperature and energy use as well as qualitative measurements of user behaviour and perceptions. Research comparing predicted energy savings and actual savings from retrofit often attribute a large proportion of any shortfall to comfort take-back. Savings can be overestimated with examples of $28 \%$ [50] and $36 \% \pm 8 \%$ attributing this to increased comfort amongst other reasons [51]. Other total direct rebound effects have shown to be in the range of $10-30 \%[52,53]$. Increases in temperature can vary considerably and depends on the level of under-heating prior to retrofit $[8,54,55]$, though these increases are generally reasonably low $\left(1^{\circ} \mathrm{C}\right.$ or less). Conversely Deurinck et al. [55] appropriates a portion of the rise in temperature to the change in building physics experienced after retrofit as opposed to the behaviour of the occupant. Furthermore, the shortfall in savings can be attributed to incorrect predictive techniques, other changes in behaviour and ranging qualities of workmanship [53,55,56]. Predicted savings can also underestimate the energy savings in what it called the 'prebound effect' [57].

\subsection{Retrofit potential}

Irish research for the National Energy Retrofit Programme found that the key obstacles to retrofitting are [58]:

1. the high upfront costs;

2. reluctance to prioritise long-term savings over short-term expenses;

3. differing priorities of landlords and tenants

4. insufficient reliable information;

5. uncertainty of the benefits;

6. shortage of certified experienced providers and contractors;

7. inconvenience; and

8. difficulty in coordinating homeowners to act collectively to reduce costs.

An analysis compiling data from several sources on Irish houses, occupancy and indoor temperatures for rural housing found that there is potential to reduce running costs and $\mathrm{CO}_{2}$ emissions by an average of $63 \%$ for pre 1979 houses and $26 \%$ for newer ones, however, this study does not account for user habits for heating [22]. It is with the overarching motivation of achieving this potential that the objectives of this investigation were formed. There is a limited understanding of how effective related policies and actions have been. This in turn stymies the development and impact of such policies. In order to gain a more complete evaluation of the scheme, a holistic approach was taken, combining quantifiable data with perceptual information. This study builds on the methodology and findings of Byrne et al. [26] by introducing the variable of the occupant. A number of houses were surveyed and monitored before and after being retrofitted with cavity or external wall insulation. Interviews with occupants were also conducted in order to gain understanding of how occupants influence the dynamics of energy consumption, in particular subsequent to a retrofit scenario.

\section{Methodology}

Energy use in similar homes can produce vast diversities in consumption. Furthermore, the potential change in energy use after retrofit is heavily dependent on a number of human factors. The study was not aimed at gaining an exhaustive understanding of human behaviour in the home. Instead, the aim was to incorporate the variable of human behaviour into the examination. This was achieved by triangulating it with monitored data and survey observations to gain a richer understanding of how the building-in-use system performs prior compared to post retrofit. It was an examination of the scheme on the ground, splitting into three phases: the survey, monitoring of the building, and an interview with the occupant. 


\subsection{Survey}

The Survey/Audit form created for this research project involved a combination of current existing residential energy assessment procedures RdSAP [59], BER [60] and CIBSE guide on energy assessments [41] along with other online home energy assessment forms [61-63]. CIBSE Guide F, section 18.3.1 [64], establishes what should be covered in an energy survey. Although some of these are clearly aimed more at the commercial sector, many of them are relevant or can be reinterpreted for domestic assessment as was the case for this investigation.

The main aim of the survey was to establish how energy is used within the home and the features and materials of the house itself. While standard practice within the field of auditing and surveying forms the foundations of the survey, this project had additional needs. One such need was for the survey to act in a complimentary manner with the monitored data. Measures of oil and gas usage as well as electricity data and room condition data could be more confidently assessed once the behaviour of the occupants was well established. In addition to the traditional walk around survey, therefore, it was necessary to question the occupant in relation to appliance and heating usage as well as movement and activity in the home. Certain questions in the survey were repeated after the retrofit works in the interview questions. This was done in order to help determine whether there were any behavioural or usage changes between the pre to post scenarios.

The final survey form was divided into the following sections: pre arrival; external inspection; sketches; and occupant questionnaire. Before arriving at the site, basic information on building and wall type was obtained from conversations with the on-site contractor, while particulars of location and orientation were gained using maps. These were verified upon arrival at the site. The external inspection involved an overview of the building allowing details such as exposure level to be observed. Sketches were made using recorded notes from the walk around in combination with photographs and included as much detail as possible on anything that influenced the efficiency of the building and thermal behaviour within it (including fireplaces, windows and radiator positions). The occupant questionnaire involved basic questions on energy usage and activity in the home as well as questions about the building itself. Upon completion of the survey, the monitoring phase began. The final survey form is available in reference [65].

\subsection{Monitoring}

Much of the basis for the monitoring methodology and equipment is outlined in Byrne et al. [26]. The monitoring share of this project was the major contributing factor in determining the immediate impact of cavity and external insulation introduced under the HES/BEH scheme. The impact included that on comfort, behaviour and energy usage. It also provided information on the immediate impact on building physics as seen in the Byrne et al. [26] case study, but as a building-in-use scenario, giving an insight into the actual impact of the scheme.

Monitoring equipment was set up during and after the survey on the first visit to the building. Equipment was set up as shown in the typical example Fig. 2 and explained as follows. Temperature and humidity sensors were positioned in the main bedroom and most frequently used room (usually the living room) in an area that gave an accurate determination of room conditions. An external sensor was also set up outside, above the ground at a location sheltered from sunlight and away from heat sources. Other rooms were also deemed suitable on a case by case basis. This helped to establish room conditions and the differential between outside and inside temperature for a given heating input. These values were also combined with the occupant interview to gauge comfort level.
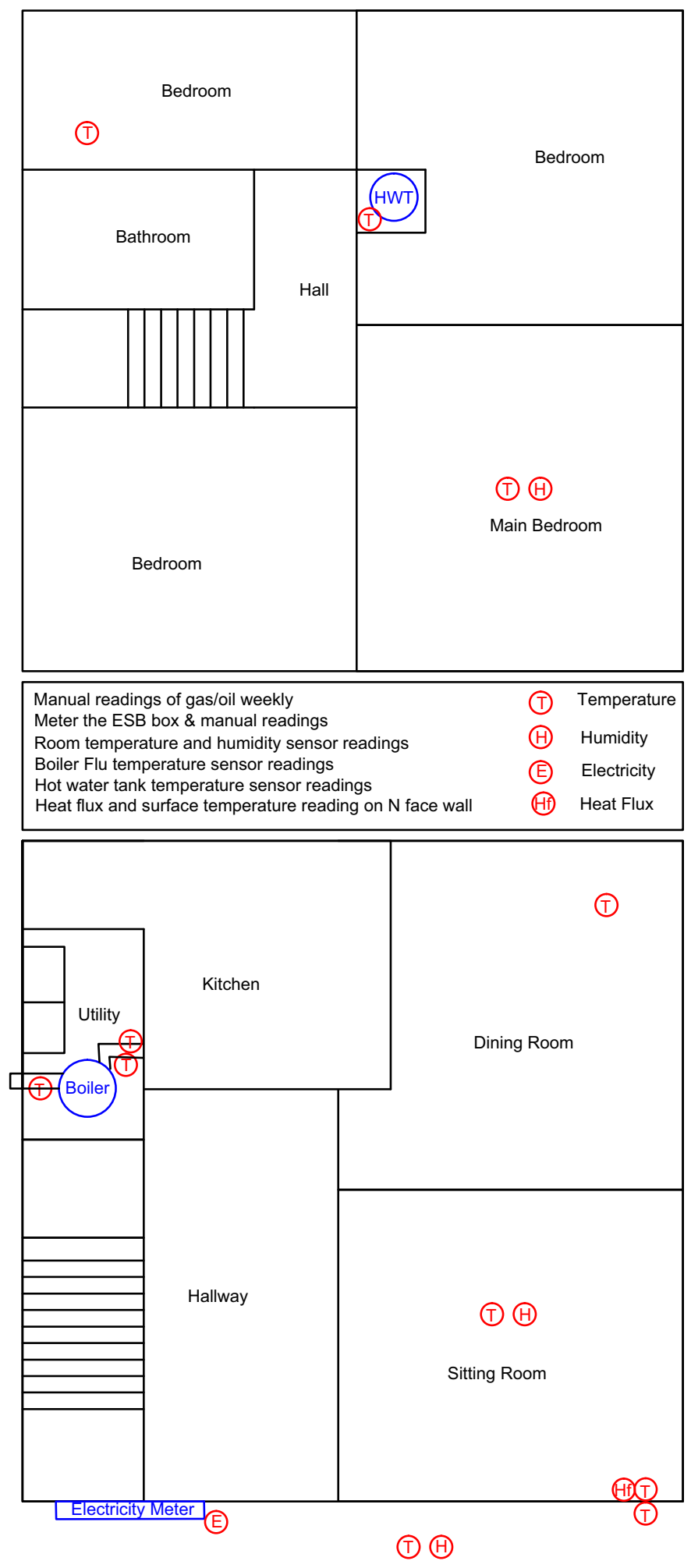

Fig. 2. Standard instrumentation of a house for monitoring.

If a boiler was present, temperature of the output flue of the boiler was monitored using a thermocouple and datalogger in order to give an indication of the use and ignition times of the heating system. The flow and return pipes for the radiator circuit were also monitored to measure the differential in temperature of the water across the boiler and thus give an indication of the heat output of the boiler. If another heating system was installed whereby the same method could not be used, the survey addressed this under 
questions regarding fuel usage, for example the number of briquettes used daily to heat the fire and operating settings and use (if any) of electric heaters.

In situ heat flow apparatus (comprising heat flux sensor, conductive paste and thermocouples was set up on a north facing wall if available as per Byrne at al. [26]. If not available, a wall sheltered from sunlight was chosen. An electricity meter was fitted on the mains supply to monitor electricity usage. Oil or gas consumption was established by weekly visual recordings of oil or gas levels. This was combined with the readings from the sensors on the boiler to determine heating usage and patterns over the monitored periods.

The equipment was set up and left in the house for a minimum of seven days before the retrofit and seven days after. If recording time passed over a week, the data is downloaded every seven days. If possible, the house was photographed with a thermal imaging camera at a time when the heating system was in use. In order to increase the reliability of the comparison, similar indoor and outdoor conditions were required. This was not possible in all site cases due to location of the building, availability of equipment and unsuitable weather conditions. Some or all of the equipment was removed during the retrofit works and re-installed afterwards depending on the time required for retrofit, and what measures were being installed. This marked the second and third visits to the property. The final day after monitoring involved removal of equipment as well as the occupant interview.

\subsection{Occupant interview}

Occupant interviews were used to gauge the occupants' perspectives as well as determine certain facts as the occupants perceived them. In addition to this, the interviews were used in combination with the pre survey and monitored findings in order to gain a richer understanding of behavioural aspects of retrofit.

The semi-structured in-depth interview was deemed most appropriate as it was considered as getting the 'best of both worlds' allowing interviewees to venture down tangential paths which could reveal important information while conserving the degree of structure determined by the interviewer [66,67]. The interviews took place on the final visit to the home after all readings were taken and the equipment had been removed. At this stage they were already aware of the background to the research from previous interactions. The interview was recorded and notes taken. The questioning began with quantitative questions, mainly the same ones posed in the initial survey to determine any changes in how the home was used over the monitored period. The bulk of the interviews involved more open-ended questions and included follow up prompts. Areas covered by the interview were as follows.

1. Demographic: To gain understanding of the customers of the scheme and give an indication of the activity levels in the home.

2. Behaviour in the home: This aspect was essential for aiding the comprehension of the monitored data. Appliance usage, space and water heating, movement within the home and activity.

3. Perception of comfort: The aim was to combine answers with monitored data in order to augment the understanding of the building before and after retrofit as well as gain an insight as to what constitutes 'comfort' for that occupant.

4. Process of retrofit: It added to the overall understanding of the barriers and drivers for retrofit as well as the consumer/retrofitpolicy interaction. Questions probed how the occupant found out about the scheme, how they decided on the retrofit options and their personal experience of the entire process.

5. Results of retrofit: Aimed at revealing the perceived improvements of the retrofits. This was mainly with regard to changes in comfort, but also whether the occupant had noticed any changes in energy usage behaviour. The questions focused on satisfaction levels. The intention of these questions was to uncover perceived barriers, drivers and potential for improvement.

Investigation of the interviews followed a grounded theory approach rather than beginning with a hypothesis and testing it [68]. Interviews were transcribed, classified and coded using the Thomas [63] method.

\subsection{Case studies}

The case studies were, for the most part, self-selecting. Weather conditions during retrofit period and the retrofit works being done limited the number of relevant cases.

Two of the houses for the study were not under the HES/BEH scheme, but were retrofitted as part of Respond Housing Authority's improvement process of social housing. These houses did not contribute to the overall evaluation of $\mathrm{HES} / \mathrm{BEH}$, but served to increase the understanding of how cavity insulation changes the behaviour of buildings. All homes were built between 1960 and 1990 and owner occupied, apart from the two Respond council houses which were built in 2000 and occupied by council tenants.

The first test house was fitted with cavity insulation and three months later with external insulation and was monitored before and after each stage. A north-facing and a south-facing room were chosen for examination on the basis that they would not be occupied over the monitored periods. The curtains were drawn and the doors closed for both rooms with agreement obtained from the occupants that they would not enter the rooms during the monitoring period. Furthermore, the occupants agreed to leave their heating on a timer and at a set power so that the heat energy provided to the house was consistent over the full monitoring period. This was specified so that a baseline understanding of the effect of insulation on the thermal behaviour of intermittently heated dwelling could be established before introducing the additional unknown of occupant behaviour. In this way, the first house acted as a semi-controlled occupied test. In all other site cases to follow the occupants were instructed to use the buildings and heating systems as they pleased over the monitored period.

\section{Results and discussion}

\subsection{Overall findings}

Table 2 summarises the findings. The headings in the table are the changes that were expected to occur due to the installation of insulation. Green denotes that the listed change was observed in the data, yellow means that no significant change occurred and red shows that the opposite of what was expected was observed. The table combines the data gleaned from all three stages of the case studies: the survey, monitoring and the occupant interview.

Overall, as highlighted by this graphic, the findings were as anticipated. Both baseline heat losses to the wall and comfort improvement to the occupant showed unanimous improvements regardless of time of year, housing type, occupancy or heating patterns. The average and baseline room temperatures showed similarly positive results. Improvements in heat retention and storage were identified in most cases either through interview or in the data.

Most disagreements with the expected results occurred around the changes in heat energy use with hours of heating per day and fuel use per day increasing or staying the same in almost half of the cases. These findings are discussed in more depth in the following sections with careful consideration of the anomalies as shown in red in the graphic. 
Table 2

Overall findings from case study house.

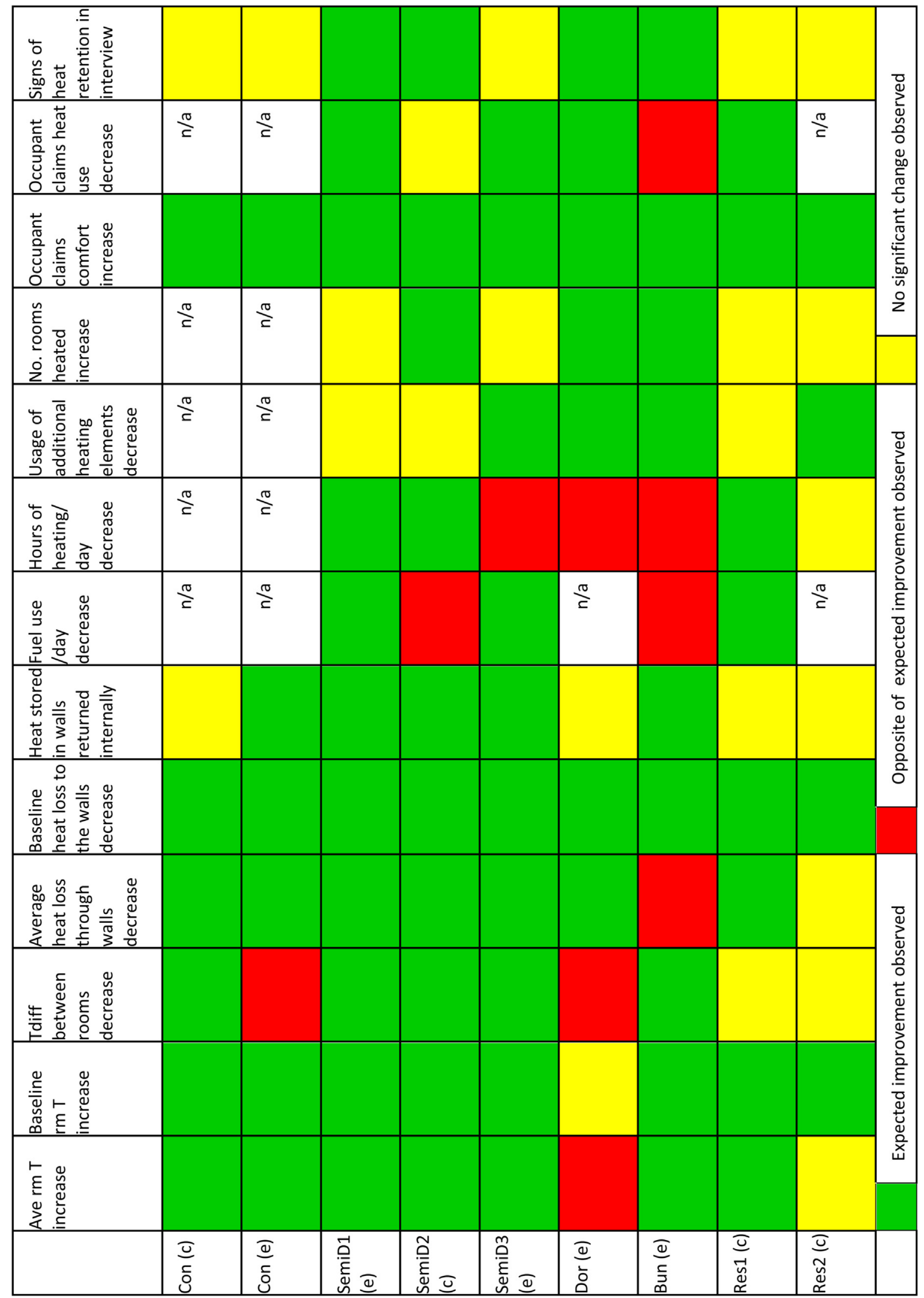




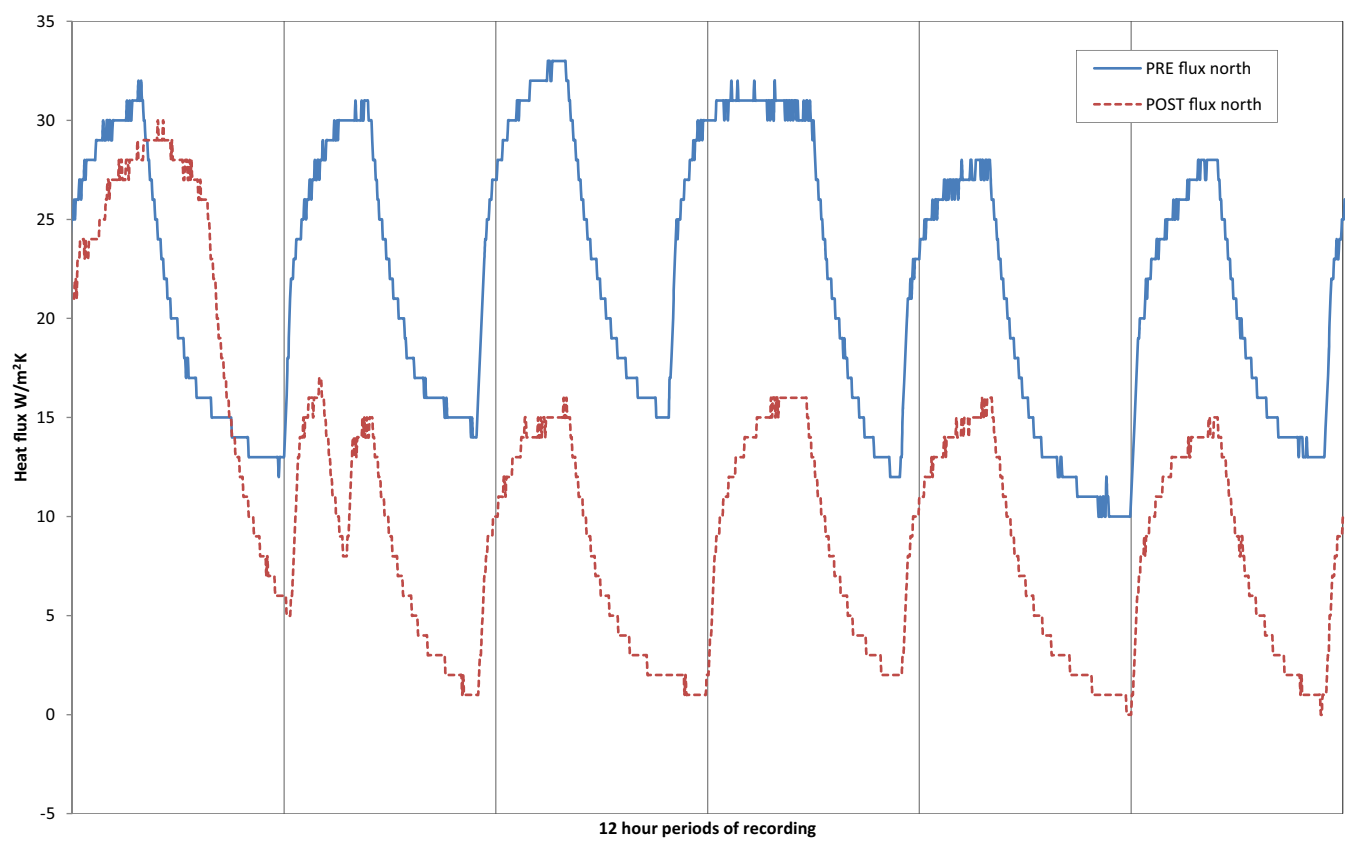

Fig. 3. Con(c) north wall, used as an example of heat flux change for cavity fill walls.

\subsection{Variables in the analysis}

Houses which obtained cavity insulation are cases Con(c), SemiD2(c), Res1(c) and Res2(c). Con(c) is the semi-controlled case as described in the Section 2.4. Con standing for "controlled heating", SemiD standing for "Semi-detached" and Res standing for "Respond Authority Housing". Data from Res1(c) is largely usable. In the case of Res2(c), the occupants did not use their heating system over the entire monitored period and so only very limited use of this data could be made.

Houses which obtained external insulation were cases Con(e), SemiD1(e), SemiD3(e), Dor(e) and Bun(e). Dor standing for "Dormer" and Bun for "Bungalow". Con(e) is the semi-controlled case, though unusually it had its cavity pumped as test case Con(c), therefore the thermal quality of the walls was already reasonable before testing began for the external insulation in Con(e).

Timeframes for comparison were chosen on the basis of encountering similar external temperature, for analysis purposes. However, as matching ambient conditions exactly was not possible, timeframes were chosen on the basis of external temperature being less (though insignificantly so) than the pre period in order to avoid overestimating the potential changes. This leads to a slight underestimation of the true changes. The only cases where this could not be achieved were in the two Respond Housing Authority buildings Res1(c) and Res2(c). Furthermore, for SemiD1(e) and Dor(e), ambient conditions were significantly colder during the post retrofit period by over $5^{\circ} \mathrm{C}$. This did not seem to affect the positive outcomes which are readily viewable in green for house SemiD1(e) in Table 2. The effects appear to be much more visible for Dor(e) in the same table.

The second, and most influential variable, was the introduction of the occupant into the analysis. Occupants used the house and heating as they pleased over the monitored period (except for Con(c) and Con(e) as discussed). This was an intentional introduction as the objective of the project was to determine actual changes in energy usage and building physics due to the retrofit measures as related to the government's retrofit scheme. While it was intentional, comparing exactly like-with-like was not possible. Instead, general conclusions could be drawn by using overall combined findings.
Thirdly, while the occupants were asked if there were any changes in the occupancy of the building over the timeframe, their recollections may not have been completely accurate and do not account for all members of the house. This means that the number of occupants per hour per day could have varied from the pre to the post case. This is an unknown variable, however, it is assumed that these changes could not have been dramatic if they were not recalled. Furthermore, because of the number of cases studied, any cases where occupancy increased post retrofit is likely to be balanced by any cases where it decreased when making generalisations.

\subsection{Heat loss}

\subsubsection{Cavity fill walls}

For the semi-controlled case of Con(c), average heat flux reduction equated to a reduction in average heat loss of $52 \%$ (north wall) and $50 \%$ (south wall) as shown in the snapshot of data Fig. 3. In the other cavity fill cases the average reduction in heat loss through the walls was $66 \%$ and $21 \%$.

As can also be observed in Fig. 3 after the initial day of heating post retrofit, the baseline heat loss through the wall can also be reduced when the insulating ability of the wall is enhanced with retrofit cavity fill. Baseline heat loss refers to the minimal or constant heat loss that is experienced through walls even when there is no heat supply present. It is shown in the Con(c) example in this figure that the baseline loss to the wall was approximately $14 \mathrm{~W} \mathrm{~m}^{-2}$ and reduced to roughly $0 \mathrm{~W} \mathrm{~m}^{-2}$ post retrofit (the south facing wall observed a similar reduction). The baseline heat lost in the other case studies also reduced to approximately 0 .

Furthermore the maximum daily heat loss through the walls decreased by a large amount for the semi-controlled case Con(c). This reduced from 32 to $15 \mathrm{~W} \mathrm{~m}^{-2}$ for the north wall. This was less observable in the other two cases.

A summary of the findings from all cavity fill cases is provided in Table 3. As discussed, in all cases the baseline heat loss to the walls reduced to at least no heat loss, or $0 \mathrm{~W} \mathrm{~m}^{-2}$, recorded at the internal surface. However, there was a negative minimum flux observed in SemiD2(c) showing that some of the heat stored in the internal 


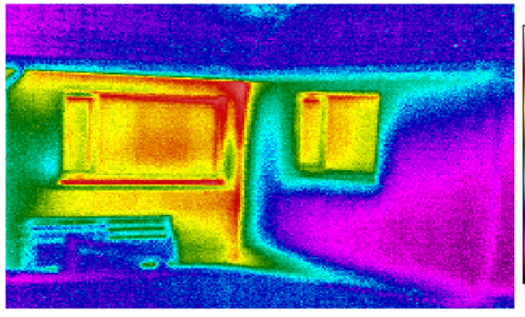

(a)

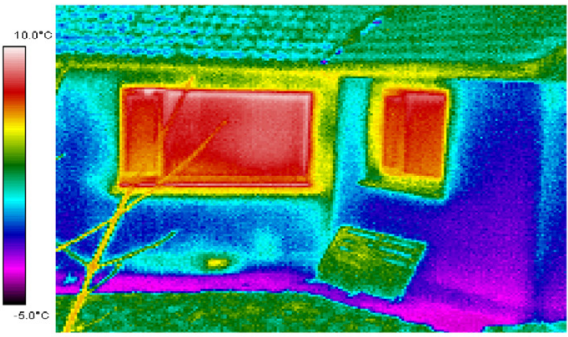

(b)

Fig. 4. Con(c) thermal image back wall pre (a) and post (b) cavity fill insulation.

Table 3

summary of thermal changes to cavity fill walls.

\begin{tabular}{|c|c|c|c|}
\hline & Change in heat loss & Change in baseline heat loss $\mathrm{W} \mathrm{m}^{-2}$ & Change in ave daily max heat loss $\mathrm{W} \mathrm{m}^{-2}$ ) \\
\hline Con(c)north & $-52 \%$ & -14 & -17 \\
\hline Con(c)south & $-50 \%$ & -10 & -16 \\
\hline SemiD2(c) & $-66 \%$ & -12 & -2 \\
\hline $\operatorname{Res} 1(\mathrm{c})$ & $-21 \%$ & -1 & 0 \\
\hline
\end{tabular}

block layer of the wall was returned to the internal space when the heating was turned off.

Thermal imaging was used to compare pre and post cases where the heating had been on for a similar amount of time and the external conditions were comparable, overcast and dry. Fig. 4 shows a thermal image of a west and north facing wall for site case Con(c) before and after insulation is pumped into the cavity. The image shows that a large portion of heat was being lost through the walls before insulation was introduced, especially on the west facing wall and at locations around windows and joints with the roof and other walls. In the post retrofit image, the overall temperature of the external wall was more uniform and cooler. It thus visually displayed the monitored findings; there was now a barrier to heat flow between the internal warm and external cool environments.

\subsubsection{External wall insulation}

For the semi-controlled case of Con(e), the average heat flux reduced by 2 and $2.6 \mathrm{~W} \mathrm{~m}^{-2}$ through the north and south walls equating to a reduction of $48 \%$ and $60 \%$ over the monitored period. It should be considered here that this house had been previously retrofitted with cavity insulation as $\operatorname{Con}(\mathrm{c})$ and therefore, it is be postulated that the impact of external insulation, had it been applied alone, could have been greater than indicated here. The remaining test cases saw reductions in heat loss of as little as $1.8 \mathrm{~W} \mathrm{~m}^{-2}$ to as high as $16.1 \mathrm{~W} \mathrm{~m}^{-2}$. These values equate to reductions of between 37 and $77 \%$ in average heat loss. However, site case Bun(e) showed an increase in heat loss of $40 \%$, though this can be explained by the dramatic change in heating usage in the building post retrofit as will be discussed in Section 3.5.1. A snapshot from

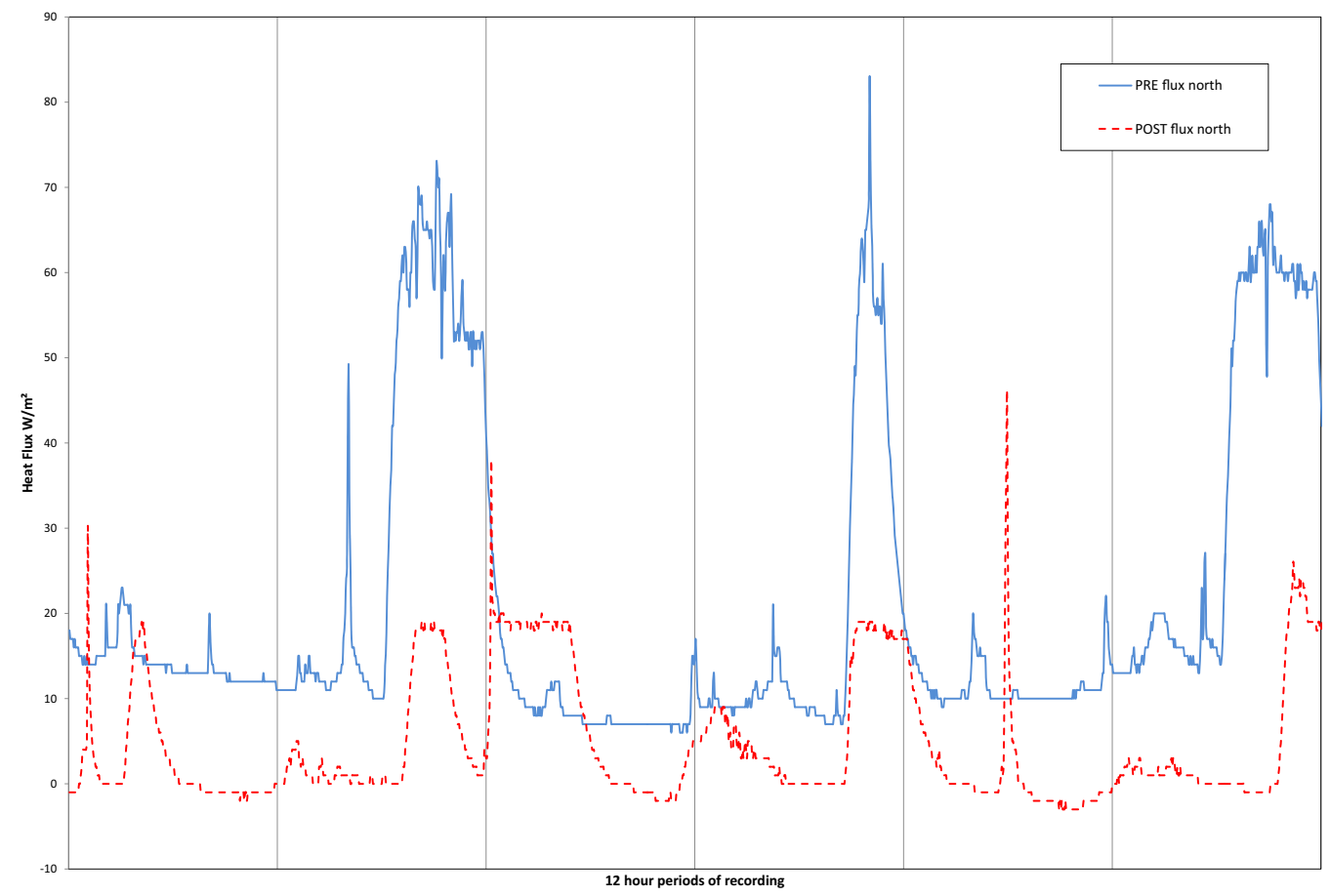

Fig. 5. Three days of recordings for SemiD1(e) as an example of heat flux change for external insulation walls. 
Table 4

summary of thermal changes to external insulation walls.

\begin{tabular}{|c|c|c|c|}
\hline & Change in heat loss & Change in baseline heat loss $\mathrm{W} \mathrm{m}^{-2}$ & Change in ave daily max heat loss $\mathrm{W} \mathrm{m}^{-2}$ \\
\hline Con(e) north & $-48 \%$ & -1 & -7 \\
\hline Con(e) south & $-60 \%$ & -5 & -1 \\
\hline SemiD1(e) & $-75 \%$ & -12 & -12 \\
\hline SemiD3(e) & $-77 \%$ & -10 & -48 \\
\hline $\operatorname{Dor}(\mathrm{e})$ & $-37 \%$ & -2 & -4 \\
\hline Bun(e) & $+40 \%$ & -3 & -6 \\
\hline
\end{tabular}

SemiD1(e) recordings is used as the example of typical changes in heat flux (Fig. 5).

The baseline heat loss was reduced in all cases, even for Bun(e) despite the increase in heating usage, to at least 0 . It should be noted here that four out of the six cases showed negative heat flux as the stored heat in the wall was returned to the inner space when the heating system was turned off contributing to an overall reduction in heat loss. This was not observed in any pre-retrofit case. This is consistent with the findings of Byrne et al. [26]. The average maximum heat loss experienced by the test walls decreased in all cases including case Bun(e). All of these reductions are displayed in Table 4

Thermal imaging was again used where possible (an example image is shown in Fig. 6). The pre image for this location shows clearly the structural ring beam as warmer than the surrounding wall areas meaning that it was acting as a thermal bridge. External insulation was introduced in the second image and the insulation now blocks heat from escaping fully to the external environment resulting in more uniform surface temperatures. Similar results are shown along the chimney flue. This house had attic insulation fitted as reflected in the decrease in external surface temperatures of the roof. Generally the external surface temperature of the wall and roof become much more uniform in the post case as the building envelope became more resistant to heat loss.

\subsubsection{Combined findings}

All residential walls in the case studies showed a reduction in the average heat loss. The range was generally lower for cavity filling (21\%-66\%) compared to external insulation (37\%-77\%). Although values vary greatly, this does present in situ evidence that the addition of cavity and external insulation reduced the amount of heat lost through the walls for the buildings examined regardless of the behaviour of the occupant. Furthermore, the continual heat loss even when the heat source is turned off was shown in the majority of the pre retrofit cases and reduced considerably to near 0 in all cases after retrofit. The implications of this are that the introduction of cavity and external wall insulation results in the walls no longer continually siphoning heat from the inner space.

The introduction of both cavity wall and external wall insulation showed evidence of harnessing the heat storage capacity of the inner mass of the wall by reducing the heat loss to the outdoor environment. The result of this is that some of the heat that is stored in the walls is returned to the inner space when the heating source is turned off. This was shown in the in-depth study by Byrne et al. [56] as well as in five out of the nine case studies presented in this paper.

\subsection{Damping/moderating and heat retention}

Overall house air temperature fluctuations became less extreme after retrofit, as exemplified by case SemiD1(e) in Fig. 7. Most of the cases experienced an average increase in indoor temperature as displayed in Table 5. However, Dor(e) decreased. This can be attributed to two causes. The first as was discussed in Section 3.1.1; the external climatic conditions worsened considerably in the post retrofit monitoring with the occupant mentioning during the interview that there had been frost observed after the retrofit works. Secondly, the data showed that there was a great variation in temperature between the ground floor and the upper, timber converted dormer portion of the house with the colder 1 st floor contributing most to the anomaly in the figures.

The temperature of different rooms also became much more uniform. The dramatic change in uniformity observed in case SemiD2(c) is justified using the interview with the occupant in which it was explained that before retrofit occurred the homeowner would alternate which rooms were heated, whereas once the house became more effective at retaining the heat, all rooms were heated. Bun(e) also showed a similarly significant increase in uniformity, though as will be discussed in Section 3.5.1, the central heating use was increased greatly after retrofit. The only in-use case that actually increased the variation in temperature experienced in the house is Dor(e). This can be explained by examining the data which shows that the converted timber loft space did not show as significant an improvement in temperatures post retrofit compared to the original portion of the house which had external insulation fitted. This resulted in an increased variation in temperatures between the ground floor and the converted dormer. The semi-controlled site case for external insulation Con(e) also displayed a significant increase in variation of room temperatures. The south facing room increased its temperature by over $3^{\circ} \mathrm{C}$ while the north facing room only increased its average temperature by over $1^{\circ} \mathrm{C}$. Despite the curtains being drawn during the test period, solar gains can still be quite influential on room temperatures with the north facing room receiving no sun.

\subsection{Impact of wall insulation on heating regime}

The impact of the retrofit on space heating was examined by comparing the average number of hours in which the house was heated using the sensor place on the boiler flue. The total fuel used was also measured where possible. This result is not as reliable because in many cases the same fuel source was used for water heating or cooking. The use of additional heating measures (such as a fire) was identified through questions to the occupant during the pre-retrofit survey and the post retrofit interview. Furthermore, it was determined during these questions if any radiators were turned off and if this changed in any way after retrofit.

Table 5

Summary of changes to the average internal air temperatures and uniformity of room temperatures in all retrofit site cases.

\begin{tabular}{llll}
\hline Cavity fill & Average $\operatorname{rm~} \mathrm{T}\left({ }^{\circ} \mathrm{C}\right)$ increase & Pre Tdiff $\left({ }^{\circ} \mathrm{C}\right)$ & Post Tdiff $\left({ }^{\circ} \mathrm{C}\right)$ \\
\hline Con(c) & +0.3 & 1.6 & 1.1 \\
SemiD2(c) & +0.1 & 3.0 & 0.3 \\
Bun(e) & +1.2 & 0.6 & 0.6 \\
External & & & \\
Con(e) & +2.3 & 0.6 & 2.8 \\
SemiD1(e) & +1.9 & 1.7 & 0.6 \\
SemiD3(e) & +2.0 & 2.3 & 2 \\
Dor(e) & -1.0 & 2.0 & 3.4 \\
Bun(e) & +2.4 & 3.3 & 0.6 \\
\hline
\end{tabular}




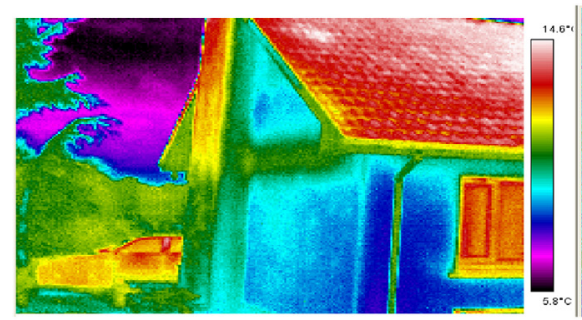

(a)

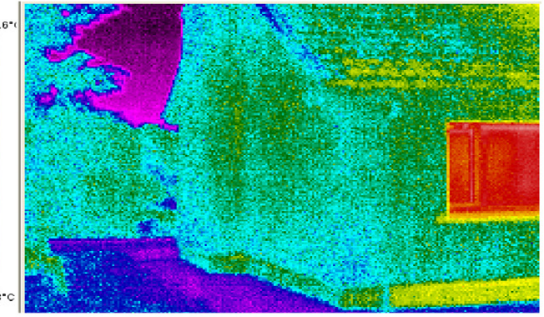

(b)

Fig. 6. Con(e) thermal image of east facing wall pre and post external insulation and attic insulation.

Table 6

change in fuel usage for all site cases.

\begin{tabular}{llll}
\hline Cavity fill & Pre heating/day & Post heating/day & Change in fuel\%/day \\
\hline Con(c) & n/a & n/a & n/a \\
SemiD2(c) & $5 \mathrm{~h} 5 \mathrm{~min}$ & $3 \mathrm{~h} 33 \mathrm{~min}$ & $+19 \%$ \\
Res1(c) & 2 h & $1 \mathrm{~h}$ & $-21 \%$ \\
External & & & \\
Con(e) & n/a & n/a & n/a \\
SemiD1(e) & $9 \mathrm{~h} 30 \mathrm{~min}$ & $4 \mathrm{~h} 22 \mathrm{~min}$ & $-62 \%$ \\
SemiD3(e) & $4 \mathrm{~h} 3 \mathrm{~min}$ & $5 \mathrm{~h} 35 \mathrm{~min}$ & $-42 \%$ \\
$\operatorname{Dor}(\mathrm{e})$ & $5 \mathrm{~h} 20 \mathrm{~min}$ & $6 \mathrm{~h} 36 \mathrm{~min}$ & $\mathrm{n} / \mathrm{a}$ \\
Bun(e) & $1 \mathrm{hr}$ & $3 \mathrm{~h}$ & n/a \\
\hline
\end{tabular}

\subsubsection{Fuel use}

Table 6 presents the changes in average hours of usage of the central heating system in the monitored data over periods of similar outdoor temperatures. The total percentage change in fuel used covers the total monitored period including times when ambient conditions are not comparable. Three out of the five uncontrolled site cases showed an increase in hour usage per day. The fuel use for Con(c) was controlled as described earlier.

Three out of the five homes, whose heating fuel use could be monitored, experienced measurable reductions in fuel used per day after retrofit. The reduction in fuel usage was 63\% (SemiD1(e)), 42\% (SemiD3(e)) and 21\% (Res1(c)). This was not at the cost of internal temperatures as these homes also experienced measurable increases in average and baseline room temperatures and all three occupants professed that they were more comfortable post retrofit.

Occupants can choose to increase their energy use in favour of increased comfort. The most relevant case being Bun(e). This occupant used coal and briquettes on the fire in the living room as a primary source of heating pre retrofit and supplemented this by using the central heating system on average once every two days for $2 \mathrm{~h}$. Post retrofit, central heating usage increased greatly to $1.5 \mathrm{~h}$ twice a day. This translates to three times the amount of heating as shown in Fig. 8 which displays the temperature of the flue on the boiler system pre retrofit in blue and post in dashed red. Post retrofit the use of the fire decreased from almost a full bucket of coal or wood and two briquettes every day to very rarely and for aesthetic reasons only. This household was of a lower income than most of the other cases, possibly with the exception of Res1(c) and Res2(c). It was also occupied by a single retiree. This combination of demographic may explain the reluctance to heat the whole house pre retrofit, however, when the system became more efficient and more affordable to heat the whole house the occupant was able to do so.

It is generally assumed that retrofit results in less energy use. This notion is complicated by the occupant's aim to achieve thermal comfort and the fact that comfort is more attainable due to

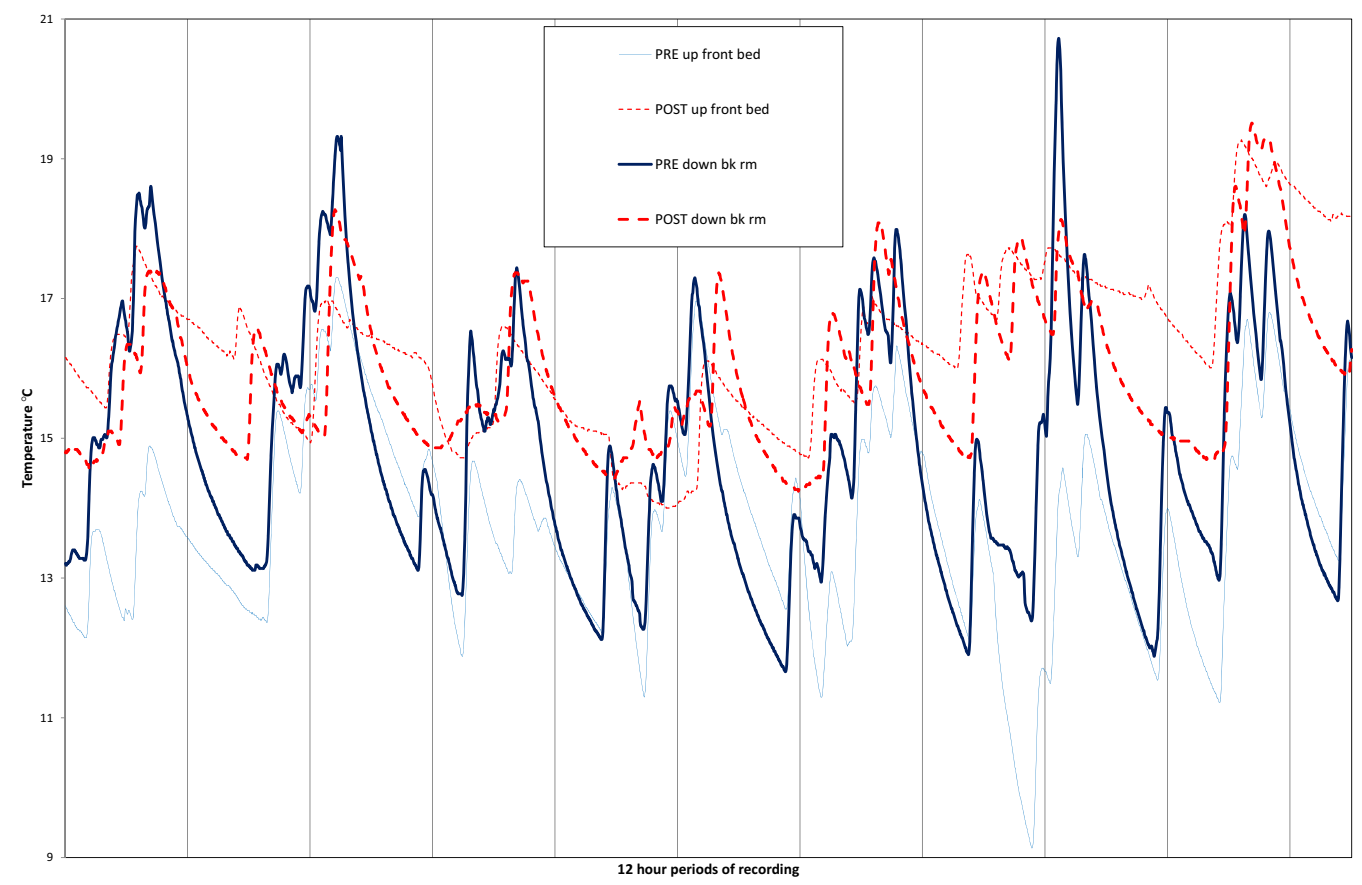

Fig. 7. SemiD1(e) comparison of graphs as an example of reduction in indoor temperature swings after retrofit. 


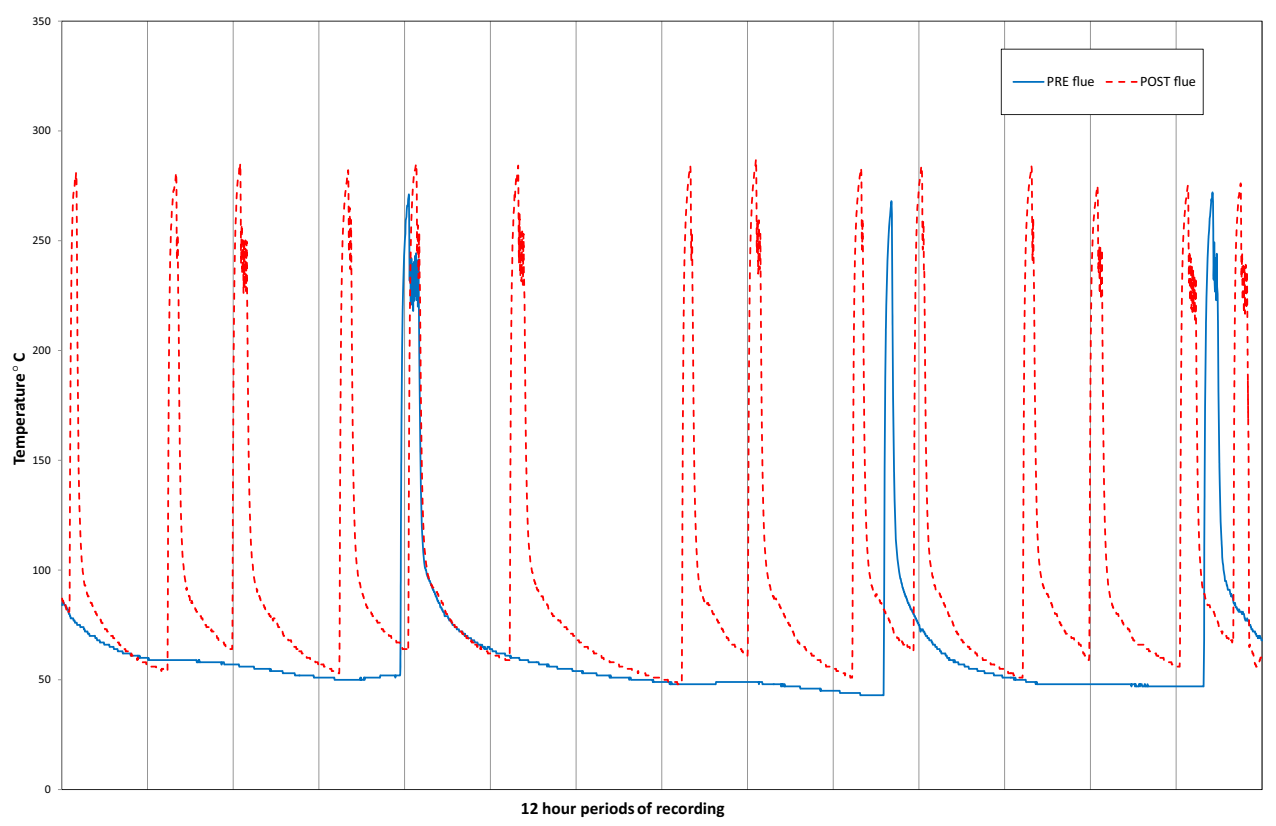

Fig. 8. Bun(e) change in central heating usage.

retrofit. Fuel used per day only reduced in three out of the five cases that could be measured. Furthermore the number of hours of central heating usage was only reduced in three of the seven cases. There was even seen to be an increase in the number of hours of central heating usage in three of the seven cases. However, these cases showed a vast reduction in the use of less efficient supplemental heat sources such as coal fires which are associated with greenhouse gas emissions.

\subsubsection{Time to reach comfortable temperatures}

Two out of the six homeowners who were interviewed reported that their homes took a shorter time to heat up (SemiD1(e) and SemiD2(c)), however, increased speed of temperature increases was not evident in the monitored data. Instead it was observed that the baseline temperature in all houses was increased therefore the time it took to reach comfort level was lessened. This was noticed by two of the occupants in the mornings for example:

Dor(e) "we don't put the heating on in the mornings at all. . . and it's lovely and warm"

\subsection{Occupant as a stakeholder}

\subsubsection{Occupant profiles and interaction}

Five interviews were conducted with clients of the HES/BEH scheme who were occupants of the case study houses. One of the interviewees had been told about the scheme from a family relative while the other four occupants could not recall how they originally learned about the scheme. They indicated that they had encountered it several times in many different forms

Two of the interviewees were very interactive during the testing period, asking questions about equipment and general energy use and insulation. These occupants claimed to also exhibit general energy efficient behaviour stating that they "always" switch off lights and appliances when not in use. These same interviewees showed signs of personally researching the retrofit procedure in some way, "I investigated it", or having attended a "Build It Yourself" show. These two interviewees cited such information sources as advertising, building shows, television programmes, discussions with contractors and the internet. The same interviewees had both 'shopped around' when it came to choosing a contractor. Each tried four different ones before deciding.
The other three interviewees were much less interactive during the surveying, monitoring and interview. They also showed signs that they did not have an interest in finding out any technical information or understanding the retrofit features or processes. Using terms such as "wasn't bothered" when asked questions in the area of increasing knowledge in energy use or retrofitting or it being "all too technical for me".

Occupants were generally satisfied with the scheme. As comfort was presented as the driver for retrofit, this was not surprising. In three cases they had been relayed positive stories about the experience from someone they knew who had already installed wall insulation using the grant scheme. There was also evidence throughout the interviews that the occupants had already discussed the positive experience with other people, or were highly likely to do so in the future. By combining discussions with the occupants and monitored data it is clear that the buildings, in general, could now be heated to a higher level, retain the heat for longer, show fewer fluctuations in internal temperatures and more uniformity in temperature throughout.

The evidenced improvement in thermal behaviour of the walls results in a changing of the internal environment and how the occupant interacts with the heating systems available. Occupant comfort levels are more easily attainable by increasing the insulating ability of the wall and harnessing its heat storage capacity. Energy saving was not cited as a motivation for any of the occupants. Therefore, this more achievable comfort was shown to result in occasional increases in energy used for space heating. Where the heating system was controlled to be the same in pre and post retrofit monitoring, the average internal temperatures rose considerably. In the cases where the occupants were free to use the heating systems as they wished internal temperatures generally rose throughout the house, the implications are that the homes were not heated to satisfactory levels of the occupants before retrofit, a hypothesis which is supported by qualitative evidence in occupant interviews.

\subsubsection{Drivers}

Unanimously and repeatedly throughout the interviews, comfort was cited as the main, if not the sole, motivation for homeowners to undergo retrofit. The ability to retrofit was then only facilitated by having the available funds. All interviewees 
professed that they would not have done the works if they did not have sufficient funds. The clients interviewed would not have taken a loan or availed of other financing mechanisms had they been on offer. The degree to which the offer of a grant motivated the homeowners to retrofit was uncertain. The interviewees offered sentiments that the grant is a driver for retrofit in reference to the general public, SemiD2(e) stating “...the only way they are going to get people to do it is if they offer the grant". In spite of these comments, the interviewees attested that they would have considered getting the upgrade even without the offered grants.

The possibility of saving money, either through bills or the added value to the home when selling, was not cited as a driver for any of the occupants. Some believed that they would be unlikely to experience savings or at least would not get back the money they invested.

\subsubsection{Limitations/reliability of interview and survey information}

Theoretically, there are two argument forms against mixed methods. There is the embedded methods argument, which believes that the decision on a particular method is a commitment to one epistemological attitude because research methods are entrenched in their respective epistemological stances. The second objection is the paradigm argument, which contends that it is not possible to combine qualitative and quantitative methodology based on interconnectedness of their epistemological assumptions.

Having a rapport built with client by the time the interview occurred could have encouraged conversation as the interviewee was more comfortable with the interviewer. However, this could have also influenced the answers given as the interviewee was more aware of the research needs of the interviewer [65]. The Hawthorne effect [66] is the theory that more positive behaviour is enacted by people being examined due to the interest shown in them. The presence of monitoring equipment could have changed how people behaved in the home. Interactions with the interviewer and equipment could also have led to a learning in energy efficiency and how the home and its envelope perform, this in turn could have influenced the behaviour within the home over the monitored period as well as influenced the answers to the interviews.

General interactions were with one occupant of each dwelling instead of all. Therefore answers may only reflect their experience of the process as well as limit the reliability of questions on activity within the house. However the interviewee tended to be the person who initiated the process to retrofit, so for the most part they were the most reliable occupant within the house to give a true reflection of the process.

\section{Conclusions}

The conclusive improvement is the reduction in total and average heat lost through the wall due to retrofitted cavity and external wall insulation under the HES/BEH scheme. How this affects the internal environment and the use of energy for space heating is less certain. It was shown that while overall comfort levels increased, not all cases showed a reduction in heating fuel use or any improvement in energy efficiency behaviour. This compares poorly with findings from the UK's 'Retrofit for the Future' data which showed that the majority of retrofit houses experienced high $\mathrm{CO}_{2}$ savings and great reductions in energy use from gas and electricity [69]. It should be noted, however, that these were innovation demonstration projects which focused on integrated solutions so cannot be compared directly with the findings from this research. CALEBRE (Consumer Appealing Low Energy technologies for Building Retrofitting) homes project, which focused on solid wall construction showed similarly positive results [67]. Findings from the CALEBRE project indicated that the order of retrofit impacts the time until payback. They recommend introducing wall insulation in the first stage as a high impact retrofit so as to yield the greatest cumulative savings.

The houses examined for this study saw a general improvement in internal temperatures in terms of uniformity, average and baseline temperatures. Both the UK and Irish clients of retrofit are driven by comfort as opposed to energy saving [70]. However, the improvement in comfort levels that the Irish client wanted from the scheme may have been greater than recipients of similar UK schemes. In all cases examined for this paper comfort levels were reported to be "excellent" on Likert-type scale post retrofit, while the majority of 'Retrofit for the Future' UK homeowners reported their comfort levels as "good" post retrofit. Although sustainability issues were not of concern to the homeowners in this study, a beneficial by-product of the retrofit was the reduction in the use of 'dirty' fuels such as coal.

It is clear that much more needs to be done in order to reach energy saving targets of $20 \%$ by 2020 or a reduction in the national energy consumption by $31,925 \mathrm{GWh}$. Projections show that the HES has contributed $365 \mathrm{GWh}$ until 2010, the GHS contributing $120 \mathrm{GWh}$ and the WHS contributing $130 \mathrm{GWh}$, and that its continuation as BEH scheme will contribute a further $3000 \mathrm{GWh}$ by 2020 [71]. This is equivalent to $9.4 \%$ of the total required energy consumption reduction by 2020 . Such projections are primarily estimated through the DEAP procedure while determination of whether targets will have been met in 2020 will be made based on actual energy provision. The site cases presented in this article suggest that the predictions for the impact of the BEH scheme are overestimated, with very little, or no, reduction in energy consumption due to wall insulation retrofit. Without more extensive similar testing it is not possible to state this conclusively.

Under the UK's Green Deal "hard-to-treat" houses such as those with solid walls which require external insulation are not covered by The Golden Rule which uses a lifetime of 25 years [72]. This presumption is reinforced by the findings in this study, that external insulation won't necessarily result in the required energy savings to offset the cost of the measure. Ireland is learning from the Green Deal's failures in the UK as consultancy is in progress for designing new financing mechanisms. However, regardless of financing mechanisms, Ireland cannot base future potential energy savings in the sector on the UK experience as Irish houses are on average of a lower thermal quality to the UK to begin with. In 2005 Irish houses emitted $47 \%$ more $\mathrm{CO}_{2}$ than the average UK dwelling [22]. It is known that the poorer the quality of the house initially, the greater the comfort take back [8]. The findings from this research suggest that Irish houses are built to a poorer thermal standard than those in the UK. Uninsulated solid wall construction constitutes $26 \%$ of houses in the UK with cavity blocks not significant enough to show in statistics [73]. Cavity blocks have a much lower thermal mass than solid walls and so the heat losses through such walls both with and without external insulation is greater. The frequency of solid walls in Ireland results in many more Irish households having to opt for the more expensive and intrusive external wall insulation, raising the cost of retrofit, increasing the payback time, and making the wall insulation grants more exclusive.

Lessons should be learned from better examples of successful retrofit schemes such as those adopted in Germany. While Irish plans appear to abandon the idea of focusing on deep retrofit, Germany's aims still include this [74]. German policy makers and advisors acknowledge that retrofit costs are higher than the resulting savings, however, costs have been reduced by clustering of buildings for retrofit to form one tender. Further to this, targets in the sector are highly ambitious, with aims to be carbon neutral in the sector by 2050 [75]. Information is the focus used to move the consumer along the process to retrofit, advancing from "uninterested" to "planning, and 'planning' to "action". These include mass 
media, information on heating bills, energy performance certificates and energy audits.

\section{Acknowledgements}

This research was funded through The School of Engineering scholarship award at Trinity College Dublin.

\section{References}

[1] IPCC, Intergovernmental Panel on Climate Change, Mitigation of climate change, in: Contribution of Working Group III to the Fourth Assessment Report of the Intergovernmental Panel on Climate Change, IPCC, 2007.

[2] E. Dennehy, M. Howley, Energy in the Residential Sector: 2013 Report, SEAI \& EPSSU, Dublin, 2013.

[3] SEAI, Annual Report 2004, SEAI, Dublin, 2004.

[4] SEAI, Annual Report 2008, SEAI, Dublin, 2008.

[5] G.Y. Yun, K. Steemers, Behavioural, physical and socio-economic factors in household cooling energy consumption, Appl. Energy 88 (6) (2011) 2191-2200.

[6] D.T. Harrje, Details of the first-round retrofits at Twin Rivers, Energy Build. 1 (3) (1978) 271-274

[7] E.L. Vine, E. Kazakevicius, Residential energy use in Lithuania: the prospects for energy efficiency, Energy 24 (7) (1999) 591-603.

[8] G. Milne, B. Boardman, Making cold homes warmer: the effect of energy efficiency improvements in low-income homes. A report to the Energy Action Grants Agency Charitable Trust, Energy Policy 28 (6-7) (2000) 411-424.

[9] J.D. Healy, J.P. Clinch, Fuel poverty, thermal comfort and occupancy: results of a national household-survey in Ireland, Appl. Energy 73 (3-4) (2002) 329-343.

[10] D. Watson, J. Williams, Irish national survey of housing quality 2001-2002, Econ. Soc. Res. Unit (2003).

[11] A.C. Kerkhof, R.M.J. Benders, et al., Determinants of variation in household CO2 emissions between and within countries, Energy Policy 37 (4) (2009) $1509-1517$

[12] O. Guerra-Santin, L. Itard, Occupants' behaviour: determinants and effects on residential heating consumption, Build. Res. Inf. 38 (3) (2010) 218-228.

[13] G. Nair, L. Gustavsson, et al., Factors influencing energy efficiency investments in existing Swedish residential buildings, Energy Policy 38 (6) (2010) 2956-2963.

[14] Building Control Act, Irish Statute Book, Office of the Attorney General, 1990.

[15] CSO, QNHS Quarter 3 2003, Module on Housing, Central Statistics Office, 2003.

[16] Department of the Environment Heritage and Local Government, Building Regulations 2005 Technical Guidance Document L: Conservation of Fuel and Energy, Minister for the Environment, Heritage and Local Government, 2006.

[17] J.P. Clinch, J.D. Healy, Domestic energy efficiency in Ireland: correcting market failure, Energy Policy 28 (1) (2000) 1-8.

[18] T. Crosbie, K. Baker, Energy-efficiency interventions in housing: learning from the inhabitants, Build. Res. Inf. 38 (1) (2010) 70-79.

[19] M.J. Pelenur, H.J. Cruickshank, Closing the Energy Efficiency Gap: a study linking demographics with barriers to adopting energy efficiency measures in the home, Energy 47 (1) (2012) 348-357.

[20] Better Energy Financing Project Team, Better Energy Financing-Barriers to the Uptake of a National Retrofit Scheme. Better Energy: the National Upgrade Programme, Department of Communications Energy \& Natural Resources (DCENR), 2013.

[21] S.F. Gamtessa, An explanation of residential energy-efficiency retrofit behavior in Canada, Energy Build. 57 (2013) 155-164.

[22] C. Ahern, P. Griffiths, et al., State of the Irish housing stock-modelling the heat losses of Ireland's existing detached rural housing stock \&amp; estimating the benefit of thermal retrofit measures on this stock, Energy Policy 55 (2013) 139-151.

[23] SEAI, Measures Paid (since Start of Scheme up to 31.01.2013), SEAI, 2013.

[24] Action Plan for Energy Efficiency: Realising the Potential COM(2006)545, Commission of the European Communities, 2006.

[25] F.P. Incropera, D.P. Dewitt, et al., Introduction to Heat Transfer, John Wiley \& Sons, 2007.

[26] A. Byrne, G. Byrne, et al., Transient and quasi-steady thermal behaviour of a building envelope due to retrofitted cavity wall and ceiling insulation, Energy Build. 61 (2013) 356-365.

[27] P.T. Tsilingiris, The influence of heat capacity and its spatial distribution on the transient wall thermal behavior under the effect of harmonically time-varying driving forces, Build. Environ. 41 (5) (2006) 590-601.

[28] P.T. Tsilingiris, Parametric space distribution effects of wall heat capacity and thermal resistance on the dynamic thermal behavior of walls and structures, Energy Build. 38 (10) (2006) 1200-1211.

[29] P. Baker, In situ U-value measurements in traditional buildings - preliminary results, in: Technical Paper 2, Glasgow Caledonian University, Glasgow, 2008

[30] Action Plan for Energy Efficiency: Realising the Potential COM(2006)545, Commission of the European Communities, 2006.

[31] SEAI, Measures Paid (since start of scheme up to 31.01.2013), SEAI, 2013.
[32] D.I. Kolaitis, E. Malliotakis, et al., Comparative assessment of internal and external thermal insulation systems for energy efficient retrofitting of residential buildings, Energy Build. 64 (2013) 123-131.

[33] F. Stazi, A. Vegliò, et al., Experimental comparison between 3 different traditional wall constructions and dynamic simulations to identify optimal thermal insulation strategies, Energy Build. 60 (2013) 429-441.

[34] J. Little, B. Arregi, Presentation on Managing moisture - the key to healthy internal wall insulation retrofits of solid walls, in: 17th International Passive House Conference 2013, Frankfurt, 2013.

[35] ISO 7730, I.S. EN ISO 7730: 2006 Ergonomics of the Typical Environment-Analytical Determination and Interpretation of Thermal Comfort Using Calculation of the PMV and PPD Indices and Local Thermal Comfort Criteria, NSAI (National Standards Quthority of Ireland), Ireland, 2006.

[36] N.A. Oseland, A comparison of the predicted and reported thermal sensation vote in homes during winter and summer, Energy Build. 21 (1) (1994) 45-54.

[37] M. Indraganti, Using the adaptive model of thermal comfort for obtaining indoor neutral temperature: findings from a field study in Hyderabad, India, Build. Environ. 45 (3) (2010) 519-536.

[38] S. Karjalainen, Gender differences in thermal comfort and use of thermostats in everyday thermal environments, Build. Environ. 42 (4) (2007) 1594-1603.

[39] D.M. Rowe, Activity rates and thermal comfort of office occupants in Sydney, J. Therm. Biol. 26 (4-5) (2001) 415-418.

[40] G.R. Newsham, Clothing as a thermal comfort moderator and the effect on energy consumption, Energy Build. 26 (3) (1997) 283-291.

[41] CIBSE, Energy Assessment and Reporting Method, CIBSE Publications, London, 2006.

[42] ASHRAE 55, A. S. o. H, Refrigerating and air-conditioning engineers, in: Standard 55: Thermal Environmental Conditions for Human Occupancy America, ASHRAE, 2010

[43] M. Frontczak, P. Wargocki, Literature survey on how different factors influence human comfort in indoor environments, Build. Environ. 46 (4) (2011) 922-937

[44] Nicol, F., M. Humphreys, et al. (2012). Adaptive thermal comfort: principles and practice London.

[45] K.-N. Kang, D. Song, et al., Correlations in thermal comfort and natural wind, J Therm. Biol 38 (7) (2013) 419-426.

[46] SEAI, Frequently asked questions. Retrieved 23 August, 2013, from http:// www.seai.ie/Power_of_One/FAQ/Energy_Efficiency/What_is_an_ideal_room. temperature_in_a_home_html.

[47] EN 15251, Indoor Environmental Input Parameters for Design and Assessment of Energy Performance of Buildings Addressing Indoor Air Quality, Thermal Environment, Lighting and Acoustics Ireland, NSAI (National Standards Authority of Ireland), 2007.

[48] J.P. Clinch, J.D. Healy, Valuing improvements in comfort from domestic energy-efficiency retrofits using a trade-off simulation model, Energy Econ. 25 (5) (2003) 565-583.

[49] Department of Social and Family Affairs, Fuel poverty action research report 5: household expenditure on fuel and electricity, in: Effectiveness of Domestic Energy-Efficiency Programmes, SEAI and Combat Poverty Agency, 2009.

[50] M. Bell, R. Lowe, Energy efficient modernisation of housing: a UK case study, Energy Build. 32 (3) (2000) 267-280.

[51] J. Scheer, M. Clancy, et al., Quantification of energy savings from Ireland's Home Energy Saving scheme: an ex post billing analysis, Energy Effic. 6 (1) (2013) 35-48.

[52] R. Haas, P. Biermayr, The rebound effect for space heating Empirical evidence from Austria, Energy Policy 28 (6-7) (2000) 403-410.

[53] S. Sorrell, J. Dimitropoulos, et al., Empirical estimates of the direct rebound effect: a review, Energy Policy 37 (4) (2009) 1356-1371.

[54] T.M. Dinan, D. Trumble, Temperature takeback in the hood river conservation project, Energy Build. 13 (1) (1989) 39-50.

[55] M. Deurinck, D. Saelens, et al., Assessment of the physical part of the temperature takeback for residential retrofits, Energy Build. 52 (2012) $112-121$.

[56] J. Rosenow, R. Galvin, Evaluating the evaluations: evidence from energy efficiency programmes in Germany and the UK, Energy Build. 62 (2013) 450-458.

[57] M. Sunikka-Blank, R. Galvin, Introducing the prebound effect: the gap between performance and actual energy consumption, Build. Res. Inf. 40 (3) (2012) 260-273.

[58] IIEA, Greenprint for a National Energy Efficiency Retrofit Programme: Jobs, Growth and Reduced Energy Costs, Media, Dublin, 2009.

[59] BRE, Energy Performance Certificate Field Sheet. Survey form version 11 for use with RDSAP V3 (2005).

[60] SEAI, Dwelling Energy Assessment Procedure (DEAP) Survey Guide: Version 2 0, SEAI, Dublin, 2011.

[61] Warm Zone Energy Assessment Sheet for North Staffordshire Warm Zone. Stoke on Trent.

[62] NIE Energy, Use Energy Efficiently: Simple Steps to Saving Energy Enniskillen (2007).

[63] Energy Saving Trust and Energy Efficiency Advice Centre, 2009, Home Energy Check. from http://www.cesul.org.uk/epp/diyhecform.htm.

[64] CIBSE, Guide F. Energy Efficiency in Buildings, CIBSE Publications, Norfolk, 2004.

[65] A. Byrne, Case Study of the Home Energy Saving Scheme: a Multidisciplinary Approach Ph.D Thesis, Trinity College Dublin, Dublin, 2014. 
[66] G. Thomas, How to Do Your Case Study: a Guide for Students and Researchers, Sage Publications Ltd., London, 2011.

[67] P. Davies, M. Osmani, Low carbon housing refurbishment challenges and incentives: architects' perspectives, Build. Environ. 46 (8) (2011) 1691-1698.

[68] D. Silverman, Doing Qualitative Research, Sage Publications, 2010.

[69] Retrofit Revealed, The Retrofit for the Future Projects - Data Analysis Report, Technology Strategy Board, Swindon, 2013.

[70] D.L. Loveday, K. Vadodaria, Project CALEBRE, A Summary of the Project and Results, L. University, 2013.

[71] Ireland's Second National Energy Efficiency Action Plan to 2020, Department of Communications Energy \& Natural Resources, Dublin, 2013.
[72] A.T. Booth, R. Choudhary, Decision making under uncertainty in the retrofit analysis of the UK housing stock: implications for the Green Deal, Energy Build. 64 (2013) 292-308.

[73] F. Tahir, I. Walker, et al., Review of potential for carbon savings from residential energy efficiency; Final report for The Committee on Climate Change Cambridge, Energy Sav. Trust (2013).

[74] K. Neuhoff, H. Amecke, et al., Thermal Efficiency Retrofit of Residential Buildings: The German Experience Berlin, Climate Policy Initiative, 2011.

[75] S. Schirmer, Efficient homes -German experiences with deep retrofit, in: IIEA ís Annual Retrofit Conference, German Energy Agency. Dublin, 2011. 